Cahiers $d u$ MONDE RUSSE

\section{Cahiers du monde russe}

Russie - Empire russe - Union soviétique et États indépendants

$48 / 4 \mid 2007$

Varia

\title{
Georges Nivat, éd., Les sites de la mémoire russe
}

\section{Laure Troubetzkoy}

\section{OpenEdition \\ Journals}

Édition électronique

URL : https://journals.openedition.org/monderusse/6129

DOI : 10.4000/monderusse. 6129

ISSN : $1777-5388$

Éditeur

Éditions de l'EHESS

Édition imprimée

Date de publication : 2 décembre 2007

Pagination : 837-840

ISBN : 978-2-7132-2148-4

ISSN : $1252-6576$

\section{Référence électronique}

Laure Troubetzkoy, "Georges Nivat, éd., Les sites de la mémoire russe », Cahiers du monde russe [En ligne], 48/4 | 2007, mis en ligne le 28 décembre 2009, consulté le 02 septembre 2022. URL : http:// journals.openedition.org/monderusse/6129; DOI : https://doi.org/10.4000/monderusse.6129

Ce document a été généré automatiquement le 2 septembre 2022.

Tous droits réservés 


\title{
Georges Nivat, éd., Les sites de la mémoire russe
}

\author{
Laure Troubetzkoy
}

\section{RÉFÉRENCE}

Georges NiVAT, éd., Les sites de la mémoire russe. Tome 1 : Géographie de la

mémoire russe. Paris : Fayard, 2007, 856 p., ill.

1 Avec ce premier volume des Sites de la mémoire russe, qui sera suivi de deux autres, commence une vaste et passionnante entreprise. Elle se situe dans le prolongement des Lieux de mémoire de Pierre Nora $^{1}$, sans en reprendre la structure, conçue pour l'exploration de la mémoire française. Pourrait-on, par exemple, étudier la mémoire « des Russie » comme l'a fait Pierre Nora pour « les France »? Ce pluriel ne serait pas sans pertinence, explique Georges Nivat dans sa préface, mais à la question des identités locales s'ajoute celle des autres composantes de l'ex-empire russo-soviétique. S'il y a bien « des Russie » et s'il y a aussi « partage de mémoire » entre la Russie et l'Ukraine ou d'autres territoires détachés, l'accent a été mis délibérément sur les facteurs d'unité de la nation russe, l'ouvrage se proposant « de déchiffrer des invariants parfois contradictoires qui font la culture russe au sens large du mot, c'est-à-dire la mémoire russe, consciente ou pas $»(\text { p. 18) })^{2}$.

2 Au mot « lieux » a été préféré celui de « sites », qui se réfère aussi à la toile d'internet. La mémoire collective est en effet semblable à un réseau en perpétuelle reconfiguration, surtout en Russie, pays de ruptures violentes qui ont entraîné des phénomènes d'amnésie, mais aussi d'hypermnésie, et où ne sont pas rares les lieux de double, voire de triple mémoire, tels que le monastère de Solovki.

3 Quarante et un spécialistes, pour la plupart russes, ont collaboré à ce premier volume, consacré à la " géographie de la mémoire russe ». Celle-ci est explorée, après une longue et substantielle préface de Georges Nivat, dans quatorze chapitres comprenant chacun de un à douze articles. Il y a là des lieux au sens propre - villes, gentilhommières, parcs et 
nécropoles, lieux sacrés populaires, églises et monastères, la Sibérie et la Russie de l'étranger - et des institutions qui ont contribué et contribuent à la formation et à la conservation de la mémoire nationale - musées, lieux d'enseignement, de lecture et de spectacle -, ce qui apparente aussi les Sites de la mémoire russe aux Lieux de savoir, dont le premier volume est paru récemment ${ }^{3}$.

4 Le chapitre consacré aux villes accorde une large place à la province. Il s'ouvre par un article général qui souligne l'ambivalence entourant la mémoire de la plupart des villes russes, longtemps éclipsées par la rivalité entre les deux capitales, Moscou ayant monopolisé, dans ce système bicéphale, le statut de ville ancienne chargée de tradition nationale, tandis que les débats des élites intellectuelles tendaient à substituer à la mémoire de chaque ville russe une histoire politique du fait urbain reposant sur un parallèle avec le développement des villes occidentales. Suivent neuf études de cas, complétées par une mise au point sur le selo, ou bourg rural russe. Si l'article sur Moscou évoque différents aspects de la mythologie de la capitale (pour la période contemporaine, le métro de Moscou aurait pu trouver sa place à côté du mythe de l'Arbat), on peut regretter que la brève étude consacrée à Saint-Pétersbourg laisse de côté l'image fantastique de la ville créée par la littérature. Les sept autres villes illustrent divers aspects du phénomène urbain russe: Perm offre l'exemple d'une ville «aux confins du monde", dont l'image est liée au mythe de l'antique Biarmija, à divers souvenirs littéraires et à la mémoire du Goulag ${ }^{4}$. Novgorod, Iaroslavl, Dmitrov et Smolensk ont été retenues pour leur rôle dans l'histoire russe, Staraja Russa pour son image littéraire ( la ville des Karamazov») et Ivanovo en tant que centre d'une industrie textile autrefois florissante. Si le choix de Novgorod s'imposait en raison de l'utopie rétrospective d'une "autre Russie» potentielle, cet aspect n'est pas pris en compte par l'auteur de l'article, qui évoque l'histoire de la cité et de ses institutions plutôt que son image dans la mémoire collective ; celle-ci est en revanche abordée dans l'article général (p.65). D'autres villes auraient pu trouver leur place dans ce chapitre: Nijni Novgorod, Kostroma, Uglič, par exemple, mais la liste serait inépuisable.

5 L'autre pôle de l'espace russe est celui des gentilhommières campagnardes, auxquelles est consacré le chapitre "La mémoire nobiliaire ", où un substantiel article général est complété par les exemples d'Ostaf'evo et de Muranovo. La gentilhommière russe est présentée dans ses dimensions historique, littéraire et esthétique, jusqu'à l'esthétisation de la mort de l'usad'ba au début $\mathrm{du} \mathrm{xx}^{\mathrm{e}}$ siècle, au statut virtuel de celle-ci dans la littérature de l'émigration et au regain d'intérêt actuel pour cet univers disparu, le tout créant " un continuum légendaire sur fond de discontinuité historique ».

6 Une approche pluridisciplinaire fait aussi l'intérêt des textes sur les «lieux de promenade et de mémoire ", parcs, jardins et nécropoles, les études de cas étant ici consacrées au parc moscovite de Neskučnyj Sad et au cimetière russe de SainteGeneviève-des-Bois. On retrouve la Russie de l'émigration dans le dernier chapitre, où Berlin et surtout Paris se taillent la part du lion ainsi que Prague, qui fait l'objet d'un texte séparé, ce qui est une bonne idée, car l'émigration pragoise est moins connue des lecteurs français.

7 Dans le vaste espace russe a été retenue une région où « la mémoire [...] fonctionne de façon particulière » (p. 303), la Sibérie, où coexistent villes de peuplement relativement ancien et villes jeunes qui ne partagent pas la même mémoire. Ce chapitre offre une analyse intéressante de la « rencontre manquée entre la culture russo-européenne et la culture du Nord de l'Asie » (p. 310), la culture autochtone ayant été depuis le début de la 
colonisation russe systématiquement ignorée. Même si le choix de se limiter au territoire de la Fédération de Russie paraît raisonnable, on pourrait imaginer en complément de la Sibérie l'exemple d'un espace détaché, mais perçu comme une enclave russe en territoire ukrainien, la Crimée, où les strates de mémoire sont particulièrement denses (Sébastopol, Yalta, guerre civile, place de la Crimée dans la littérature russe, sans parler des mémoires grecque, scythe et tatare mêlées à la mémoire russe); cette région est toutefois évoquée passim, comme on peut le voir en consultant l'index des noms géographiques.

Un des mérites de cet ouvrage est de montrer la coexistence dans la mémoire russe de la culture religieuse héritée de l'époque prépétrovienne et de la culture profane occidentale introduite à partir du début $d u x \mathrm{XVII}^{\mathrm{e}}$ siècle. L'Église et la culture orthodoxe sont largement représentées, dans les chapitres " Églises et monastères russes », " Les grandes écoles de l'Église» et "Le cycle liturgique orthodoxe russe». Dans le premier, un panorama général est suivi par la présentation de six monastères (dont la Laure des Grottes de Kiev ${ }^{5}$ et le monastère des îles Solovki, qui fut aussi l'embryon du Goulag) et par un article sur les cathédrales Sainte-Sophie de Kiev et de Novgorod. Le chapitre sur les écoles ecclésiastiques apportera beaucoup aux lecteurs français, peu familiers avec les grandes figures de Pëtr Mogila, des frères Lihudis, de Feofan Prokopovič, avec le rôle des Académies de Kiev et de Moscou et leurs rapports complexes avec la culture catholique. Ici aussi, la mémoire russe émigrée est présente, dans un texte sur l'Institut Saint-Serge à Paris.

9 Du côté de la culture profane, le chapitre sur les lieux d'enseignement rappelle que les universités sont en Russie un phénomène moderne, qui prend ses racines, non dans la culture médiévale comme en Occident, mais dans les réformes de Pierre le Grand. Ont été retenus pour les études de cas les universités de Moscou et de Saratov, l'Institut pédagogique d'Elabuga (ce dernier article pourrait aussi bien trouver sa place dans le chapitre sur les villes) et le lycée Maj de Saint-Pétersbourg. Si le choix de consacrer un texte séparé à l'université russe après 1917 paraît pleinement justifié, étant donné le changement radical des objectifs et du contenu de l'enseignement, il n'était peut-être pas nécessaire de faire de même pour l'université de Moscou. On s'attendrait en revanche à trouver mentionné le nom de Granovskij, ainsi que la Sainte-Tatjana, fête commémorant la fondation de l'université de Moscou, autrefois entourée de tout un folklore, délaissée à l'époque soviétique et actuellement remise à l'honneur.

Avec le chapitre sur les musées, nous sommes au cœur de la question du rapport entre histoire et mémoire. Trois textes sont consacrés à l'Ermitage (dont un sur la dynastie des Petrovskij et un du directeur actuel) ; l'exemple du musée national d'Histoire de Moscou pose le problème de la conception de l'histoire nationale comme histoire de l'État ou comme histoire du peuple et montre les rapports mouvementés, à l'époque soviétique, entre mémoire historique officielle et muséologie ; celui du musée d'histoire politique de Saint-Pétersbourg évoque à la fois le souvenir d'un bâtiment célèbre (l'ancien hôtel particulier de MatildaKšesinskaja), sa réquisition et les réécritures successives de l'histoire soviétique, tandis que d'autres articles mettent en lumière l'importance particulière qu'ont en Russie les musées d'écrivains et leur rôle parfois paradoxal (le musée Dostoevskij comme refuge de l'underground pétersbourgeois).

Une approche historique plus traditionnelle prévaut dans les chapitres consacrés aux bibliothèques et au théâtre, qui contiennent une quantité d'informations précieuses, 
mais peu hiérarchisées (peut-être faudrait-il un regard extérieur pour apprécier l'importance considérable du théâtre dans la vie russe, y compris à l'époque soviétique).

Mine d'informations et vaste panorama de la culture russe, l'imposant ensemble des Sites de la mémoire russe est conçu de façon à concilier présentation synthétique et exemples précis, offrant parfois des aperçus originaux sur des domaines inattendus (les noms des navires de guerre, la mémoire de la porcelaine russe). Les chapitres sur la mémoire païenne et sur le cycle liturgique orthodoxe abordent des questions importantes, qui auraient peut-être gagné à être croisées, de façon à montrer la persistance dans l'orthodoxie russe de fragments de la mémoire païenne (Élie associé à Perun, la bénédiction des chevaux à l'occasion de la Saint-Flor-et-Lavr, les fêtes religieuses appelées « Sauveur du miel », « Sauveur des pommes » et « Sauveur de la toile »...). On se prend à rêver, en lisant ce premier volume consacré à la géographie, à la mémoire de la steppe et à l'opposition entre steppe et forêt, brillamment illustrée par Turgenev et Ključevskij, ou à un chapitre sur les fleuves (la Volga, le Dniepr, le Don, les fleuves sibériens ; c'est du reste un fleuve, le Iajk, rebaptisé Ural après la révolte de Pugačev, qui a inauguré la pratique des changements de toponymes pour raisons politiques). Mais le propre de ce genre d'ouvrage est d'éveiller une insatiable curiosité. L'index des noms géographiques permet là encore de construire des parcours supplémentaires, et l'on trouve par ailleurs évoqués dans la préface de Georges Nivat bien d'autres sites, de Paleh, choisi comme exemple liminaire, à Babij Jar et Černobyl, en passant par le Pomorié, la dernière guerre, Sébastopol, le paysage et la langue, le mythe scythe, la statuaire de Saint-Pétersbourg et la question récurrente de la dualité de la Russie.

Les Sites sont une somme qui invite spécialistes et amateurs à se promener longuement en ligne droite, en zigzag ou par incursions successives - dans l'espace mémoriel russe, en attendant les volumes suivants, dont le contenu ne nous est pas révélé, mais dont on apprend que le dernier consacrera un chapitre à l'oubli, indissociable de la mémoire, mais qui, au siècle dernier, fut le produit d'une « fabrique d'amnésie organisée ».

\section{NOTES}

1. Pierre Nora éd., Les Lieux de mémoire, P. : Gallimard, 1984-1992, 7 vol. I. La République ; II. La Nation; III. Les France.

2. Il aurait sans doute été utile de rappeler à ce propos la différence que fait la langue russe entre les termes russkij et rossijskij, difficilement traduisible en français.

3. Christian Jacob, éd., Lieux de savoir. I. Espaces et communautés, P. : Albin Michel, 2007.

4. Curieusement, Perm-36, l'un des très rares musées du Goulag en Russie, n'est pas mentionné dans l'article, mais il l'est dans la préface de G. Nivat (p. 15). Dans le passage sur l'art local traditionnel, la traduction «style animalier » (pour zverinyj stil') aurait été préférable à «style bestial ».

5. Petit problème d'harmonisation : selon les articles, le mot Laure, qui désigne un monastère de première importance, est écrit tantôt avec un L majuscule, tantôt avec un 1 minuscule. 